\title{
Zone-Based Indoor Mobile Noise Monitoring
}

\author{
Samah Almutlaq \\ College of Computer \& Information \\ Sciences \\ King Saud University, Riyadh
}

\author{
Eiman Kanjo \\ School of Science and Technology, \\ Nottingham Trent University \\ Nottingham, UK
}

\author{
Lilac Alsafadi \\ College of Computer \& Information \\ Sciences \\ King Saud University, Riyadh
}

\begin{abstract}
High noise levels are increasing every day. The rapid development of most world economies has encouraged most countries to move towards industrialization. Some of the sources of noise are indoor appliances within our homes and offices. There are also outdoor sources of noise that cause discomfort examples include traffic, construction sites and factories. This paper looks at the new approaches adopted in the monitoring of noise emission levels. It adopts an approach which involved the use of mobile phones to measure and monitor indoor noise exposure in four vital areas. Mobile phones were used to improve the methods of collecting environmental data.
\end{abstract}

Keywords-component; Noise Monitoring, Participatory sensing, Sensor, Noise Pollution, Mobile phone

\section{INTRODUCTION}

Noise at everyday's places such as home, work or hospital can cause hearing loss which can be ephemeral or perpetual. While people may recover from short-term deafness after abandoning a noisy place, those who continue to be exposed to loud noise are likely to endure permanent damage. This includes muffled hearing, difficulties keeping up with conversations. A number of tools were developed recently to allow people to collect data using their mobile phones at higher granularity levels $[1,3,4]$. These tools take advantage of mobile phones' microphone and turn them into nose sensors. These tools are being used in urban settings and aimed at environmental noise near roads and busy areas. However using similar tools for indoor noise monitoring have been overlooked by researchers.

This paper utilizes the pervasiveness nature of mobile phones. It uses mobile noise detection named NoiseSpy [3] for urban noise monitoring and facilitate it for a set of experiments in indoor places including: work offices, schools, home and hospitals. The study aims at creating environmental awareness of noise pollution indoor and provides practical guidance on how the National Standard for Occupational Noise can be achieved, and hence improved.

\section{BACKGROUND AND RELATED WORKS}

Traditionally, scientific studies concentrated on outdoor noise exposures. Most of people daily exposure to many noise pollutants comes through hearing of indoor noise. Indoor exposure is mainly through internal household. Silvia Santini case study provides a Nosetube [4], a project focused on promoting a participative outdoor noise pollution monitoring platform to empower residents, as well as governmental agencies and non-governmental organizations to advance their level awareness into the issues relating to urban noise pollution. An Australian discovered an application known as Earphone. It is free to download this application. Application developer asserted that the application is useful when setting up estates and schools [2]. The other type is Nosetube where members participate and transmit data of noise levels to a community server. The other mode of mobile noise detection is the NoiseSpy [3]. An individual's phone that has any of the above applications will identify his predefined source of noise.

The static sensors are limited to certain areas this makes the data collected insufficient. Static data sensors are expensive to set up. They require a lot of human and financial input to set up these centers. Participatory sensing [5] in this aspect, allows personal phones to act as mobile sensors carried by humans and not placed at static areas.

\section{EXPERIMENTS AND TESTS}

Four experiments were carried out in order to assess the noise level indoor. These experiments were carried out at four different places including, university offices, residential homes, school classrooms and hospital units. In each building, data were collected in different zones and the measurements were compared against each others.

\section{A. Experiment of Noise Levels at University Offices}

Noise is intrusive factor especially at offices mainly by loud conversation among employees, or even from other sources including printers, computer CPU, stamping, and stapling. The experiments were carried out in normal traffic conditions for two weeks, over three hours from 4:00 - 7:00 p.m. during evening classes. Noise levels at the academic office rise up to $60 \mathrm{~dB}$ during peak time when students around. The scatter plot of noise illustrates noise greater than $55 \mathrm{~dB}$ in red is the large variation can be seen in the plot.

While the noise level is less in the administrative office, recorded at greater than $35 \mathrm{~dB}$ and below $60 \mathrm{~dB}$ in red, which is of less variation when compared to the academic office. The mean value of noise measurement at university offices on average is not significantly different at both the places in the university. It is $20 \mathrm{~dB}$ for the academic office and the administrative office. The highest variation is observed at the academic office. A high standard deviation indicates that the data points are spread out over a large range of values. In general, noise standards at work vary according to the workplace, where it cannot develop a single standard for all workers.

The American Society of Hearing and Air Conditioning Engineers recommends that offices have noise range criterion between $49 \mathrm{~dB}$ and $58 \mathrm{~dB}$ [7], in comparing this with the average at the university under study in Riyadh this has 
exceeded the limit by a small margin. And for short period of time, which might be deemed as acceptable. However actions still need to take place to decrees the level of noise to lower levels.

\section{B. Experiment of Noise Levels at Residential Homes}

In order to reduce the impact of outdoor noise sources, the noise measurement was executed in a position half meter from open window, and two meter above ground. The mobile phone runs noise monitoring in different places in the resident to collect noise level at several positions.

The study took place in two residential areas: first one is noisy neighborhood in which close to a busy road that has heavy traffic most of the day and even close to construction areas, and the second one is a quiet neighborhood. The average noise across these two areas are wide differ since it is $22.68 \mathrm{~dB}$ at the living room, and $17.82 \mathrm{~dB}$ at bed room in the quiet area resident, and is about $44.21 \mathrm{~dB}$ at noisy area resident. This study shows that noise is almost twice as it is in the quiet area, which is more than what should be for an ideal and healthy environment. WHO 40 decibel (dB) in average at night [6].

Results show that the noise level is between $30-40 \mathrm{~dB}$ at the resident close to noisy area and about $10-35 \mathrm{~dB}$ at the resident in quite area. This indicates that the sleepers in Riyadh city in either cases noisy or quite neighborhood are exposed to night noise levels above $25 \mathrm{~dB}$ and under $45 \mathrm{~dB}$. Most of the noise density in the quite area will be in the early morning hours from 08:00 a.m. to 11:00 a.m. which may increase person negative mood besides its health impact mentioned above. The peak time of noise is from 11:00 a.m. to 02:00 p.m.

\section{Experiment of Noise Levels at Hospital}

The WHO guidelines recommended that hospital noise should not exceed $40 \mathrm{~dB}$ for daytime and $35 \mathrm{~dB}$ for night [6]. We conducted an experiment over the three unit in the hospital; intensive care unit, hematology clinic, and general pediatric clinic. The experiment was taken over three hours, we tried to take the busiest hours with patients where it is from 12:00 p.m. to 03:00 p.m. We found that there is recording for noise above $40 \mathrm{~dB}$ more than two thousand times in 24 hours. This readings is exceeds the acceptable noise levels recommended by WHO.

Monitoring noise in the Hospital units for 24 hours gives varies readings of noise. Noise remains $44.15 \mathrm{~dB}$ from 03:00 p.m. till 06:00 p.m., than it is decreases to around $30 \mathrm{~dB}$ after 07:00 p.m. in the evening until 05:00 a.m. for the next day. The results show that the hematology unit in the hospital is noisier than the pediatric clinic, which was unexpected. The high level of noise in the hematology clinic was produced by the screening devices.

\section{Experiment of Noise Levels at School}

Noise in school can increase stress levels among students and hence affect their performance. In the present study, it is clear that level of noise largely exceeds the WHO standard value of 35 Decibel $(\mathrm{dB})$ in governmental schools and rental schools buildings at different periods. Nonetheless, WHO guidelines for maximum noise levels in classroom is $35 \mathrm{db}$ and $55 \mathrm{db}$ in outdoor playground [6].
To have a close look at noise levels in schools we set up an experiment at a primary school in Riyadh. Noise levels during noisy class activity, teacher talking while the class quiet, quiet class with Air Conditioning on full power, and empty class. It is clear that the noise levels were the highest when the teacher was given instructions while the children were busy with their class activity (up to $61 \mathrm{~dB}$ ). Background noise in empty classrooms was in the range of 32 to $40 \mathrm{~dB}$ due to wind slipping through windows, slammed doors, and from next rooms at the school the noise level is from 32 to $40 \mathrm{~dB}$.

Another experiment in a secondary school with quiet surroundings showed that the average of the noise level in the primary school is $33 \mathrm{~dB}$. This shows that there is noise even with the removal of most sources of noise. Occupied classrooms noise monitoring show that even if the classroom were quiet and relatively students silent, the noise average 34 $\mathrm{dB}$. In both primary and elementary schools, the typical noise level in occupied classroom increases $10 \mathrm{~dB}$ than an empty classroom. The background noise is still an important source of noise in classrooms. The experiment shows that the level of noise in primary schools increases by average of $32 \mathrm{~dB}$ than in the secondary schools.

\section{CONCLUSION}

When we compare the indoor noise level at the four environments under study; hospital, home, school, and the university, we find that the school is the most noisy place since the children activities are the most important sources of noise. After school comes home where TVs, vacuum cleaner and washing machines are the main source of noise in homes. The third noisy place is the offices and followed by hospitals. The fact that hospitals are less noise does not mean that it is the ideal since noise in the hospital under study exceeds the noise recommendations as mentioned above. Experiments and observations have shown that there are six main sources of noise involving in all the four environments which are cars, airplanes, sounds of nature in general, the sound of the use of any tool or device such as a laptop, and constructions around the area.

\section{REFERENCES}

[1] Maisonneuvea, N., Stevensb, M., and Ochaba, B. Participatory noise pollution monitoring using mobile phones. Information Polity 15, 51-71, 2010.

[2] O. Renn, T. Webler and P. Wiedemann, A need for discourse on citizen participation. In Fairness and Competence in Citizen Participation: Evaluating Models for Environmental Discourse, chapter 1. Kluwer Academic Publishers, October 1995.

[3] Kanjo, E., NoiseSPY: A Real-Time Mobile Phone Platform for Urban Noise Monitoring and Mapping, Journal of Mobile Networks and Applications, Volume 15 Issue 4, August 2010

[4] Santini, S., et al, On the Use of Sensor Nodes and Mobile Phones for the Assessment of Noise Pollution Levels in Urban Environments, Proceedings of the 6th international conference on Networked sensing systems Pages 31-38, June 2009.

[5] J.A. Burke, D. Estrin, M. Hansen, A. Parker, N. Ramanathan, S. Reddy and M.B. Srivastava, Participatory Sensing. In World Sensor Web Workshop (WSW06) at ACM SenSys06, October 31, 2006, Boulder, CO, USA, October 2006.

[6] WHO. Guidelines for community noise. Available at: http://www.who.int/docstore/peh/noise/guidelines2.html (Accessed Mar/16/ 2011).

[7] Hemp, W. E. ; Glowatz, M. ; Lichtenwalner, C. P. Curing the Noisy Office. Occupational Hazards; Occupational Hazard; 57, 8; 36, 1995. 